\title{
Pengaruh strategi komunikasi media sosial instagram terhadap brand equity, brand attitude, dan purchase intention
}

\author{
Tekrisna Khair' ${ }^{1}$ dan Ma'ruf ${ }^{2}$ \\ ${ }^{1,2}$ Universitas Andalas, Padang, Indonesia
}

\begin{abstract}
ABSTRAK
Fenomena pesatnya pertumbuhan media sosial saat ini memunculkan sebuah trend baru di mana perusahaan atau pelaku UKM menggunakan media sosial, baik sekadar untuk berkomunikasi maupun untuk memsarkan produk atau jasa mereka. Saluran media sosial menawarkan cara baru bagi perusahaan atau UKM dengan konsumen untuk saling terlibat satu sama lain. Beragam jenis media sosial dimanfaatkan sebagai tools dalam strategi komunikasi pemasaran suatu perusahaan. Salah satu media sosial yang saat ini umumya digunakan adalah Instagram. Instagram dianggap sebagai media sosial terpopuler untuk menjadi salah satu alat pemasaran dalam menciptakan dan meningkatkan kesadaran konsumen terhadap suatu brand. Tujuan penelitian ini adalah mengetahui pengaruh dari bentuk komunikasi media sosial Instagram yaitu firm-created content dan user-generated content terhadap brand equity, brand attitude dan purchase intention pada follower akun Instagram Madre (@madre_parka). Penelitian ini merupakan penelitian explanatory dengan pendekatan kuantitatif dan dilakukan dengan menggunakan metode survei. Ukuran sampel pada penelitian ini adalah sebanyak 208 responden yang dikumpulkan menggunakan metode random sampling dan teknik "purposive sampling" dengan kategori follower akun Instagram @madre-parka, usia 18 - 41 tahun dan bukan reseller dari Madre. Kusioner digunakan sebagai alat instrumen utama dalam pengumpulan data dengan menggunakan skala Likert 1-5 dibuat dalam google form. Analisis menggunakan Structural Equational Modeling dengan alat analisis data menggunakan AMOS. Hasil penelitian menunjukkan bahwa firm-created conten dan user-generated content yang dilakukan Madre berpengaruh positif dan signifikan terhadap brand equity dan brand attitude, kemudian brand equity dan brand attitude berpengaruh positif dan signifikan terhadap purchase intention.
\end{abstract}

Kata-kata kunci: komunikasi; media sosial; brand equity; brand attitude; purchase intention

\section{The effect of communication strategies on brand equity, brand attitude and purchase intention through instagram}

\begin{abstract}
The phenomenon of social media at this time raises a new trend in which companies or SMEs use social media both as a communication media and as a marketing media. Social media channels offer new ways for companies or SMEs with consumers to engage with each other. Various social media platforms have become a natural part of a company's marketing communication strategy. One of them is Instagram. Instagram is one of the most popular social media in Indonesia. Instagram is a marketing tool in creating and increasing consumer awareness of a brand. Therefore, the purpose of this study was to know the influence of Instagram social media communication forms, namely firm-created content and user-generated content on brand equity, brand attitude and purchase intention on Instagram account followers of Madre (@madre_parka).The research was an explanatory study with a quantitative approach with survey method. Samples in this study were 208 respondents collected using the random sampling method with a purposive sampling technique with the follower category Instagram @ madre-parka account, ages 18-41 years and not a reseller from Madre. Using questionnaire as a main instrument in data collection using a Likert scale of 1-5 is made into the Google form. Analysis using Structural Equational Modeling with data analysis tools using AMOS. The results showed that firm-created content and user-generated content conducted by Madre had a positive and significant effect on brand equity and brand attitude, then brand equity and brand attitude had a positive and significant effect on purchase intention.
\end{abstract}

Keywords : communication; social media; brand equity; brand attitude; purchase intention

Korespondensi: Tekrisna Khair, S.IIP. Universitas Andalas. Jln Perintis Kemerdekaan No. 71 Jati Padang 25129.Email: isnakhaira88@gmail.com 


\section{PENDAHULUAN}

Pesatnya perkembangan teknologi internet di masyarakat memudahkan manusia dalam berkomunikasi di mana pun dan kapan pun tanpa dibatasi oleh jarak dan waktu. Menurut hasil survei Hootsuite pada tahun 2019 dari total populasi penduduk Indonesia yaitu 268,2 juta jiwa, 56\% nya adalah pengguna internet yaitu sekitar 150 juta jiwa (Kemp \& Simon, 2019).

Penggunaan internet salah satunya adalah untukmedia sosial. Teknologi inimemungkinkan seseorang atau kelompok berkumpul secara virtual, saling berbagi informasi, melakukan pencarian, dan berkomunikasi. Dari survei yang dilakukan oleh Hootsuite tahun 2019, di negara ini pengguna media sosial mencapai 150 juta jiwa. Jumlah itu setara dengan 56\% populasi penduduk Indonesia. Artinya, semua penduduk Indonesia yang menggunakan internet telah menggunakan media sosial juga (Kemp \& Simon, 2019).

Platform-platform media sosial yang ada memang telah sangat dimanfaatkan untuk strategi pemasaran perusahaan, terutama di perusahaan kecil menengah (UKM) (Virtanen, Bjork, \& Sjostrom, 2017). Fenomena pesatnya pertumbuhan media sosial, memunculkan sebuah trend baru pada perusahaan ataupun UKM dalam bentuk dampak positif berupa efektifitas dan efesiensi.
Media sosial menawarkan cara baru bagi perusahaan dan pelanggan untuk saling terlibat satu sama lain (Schivinski \& Dabrowski, 2015). Dengan adanya media sosial, perusahaan berharap dapat melibatkan diri mereka dengan para konsumen, dan dapat mempengaruhi persepsi individu tentang produk mereka. Perusahaan berusaha membangun komunikasi dengan pelanggan melalui firm-created content. Firm-created content adalah komunikasi dibawah kendali suatu brand apakah itu perwakilan dari brand itu sendiri atau dari pemasaran (Bruhn, Schoenmueller, \& Schafer, 2012).

Firm-created content membantu perusahaan untuk membuat, memelihara, dan memperkuat hubungan mereka dengan target pasar mereka (Poulis, Rizomyliotis, \& Konstantoulaki, 2018). Ini dapat dilihat bahwa firm-created content memiliki efek positif yang kuat pada penjualan, dan akhirnya memberikan keuntungan bagi perusahaan, serta memberikan kontribusi dalam membangun popularitas suatu brand (Poulis et al., 2018).

Di sisi lain media sosial juga telah membawa revolusi baru, baik dalam berinteraksi, berpartisipasi, bekerjasama, dan berkolaborasi. Aplikasi ini melibatkan user-generated content dan berhubungan dengan orang-orang melalui banyak orang, dan bukan sekedar pendekatan 
tradisional (Barlow, 2015).

Pada arena online, konsumen tidak lagi sekedar penerima informasi pasif. Peran mereka bukan hanya pembaca atau pendengar, namun sekaligus menjadi pengamat, bahkan editor serta pembuat konten (Murphy, 2014). Hal tersebut dikarenakan komunikasi media sosial yang dibuat oleh perusahaan terkadang dapat dimanipulasi, dan dikendalikan oleh perusahaan, maka kemunculan user-generated content sangat penting. Adanya user-generated content menjadikan pelanggan dapat saling bertukar informasi dan berbagi pengalaman terkait brand. User-generated content telah muncul dengan luar biasa di mana individu dengan minat yang sama dapat dengan mudah berinteraksi (Bashir, Ayub, \& Jalees, 2017).

Firm-created content dan user-generated content merupakan kegiatan dalam membangun brand. Suatu brand akan menjadi lebih kuat dengan memberikan pengetahuan tentang brand di benak konsumen (Bashir et al., 2017). Media sosial menjadikan perusahaan memiliki kontrol penuh terhadap firm-created content yang mereka ciptakan dan mereka dapat menggunakannya secara positif untuk mengembangkan brand equity, dan sikap terhadap brand (brand attitude) sehingga menimbulkan keinginan untuk membeli produk yang ditawarkan (purchase intention).

Karakteristik ini memungkinkan media sosial tidak hanya sesuai untuk organisasi besar, tetapi juga sesuai untuk perusahaan kecil dan menengah (Kaplan \& Haeniein, 2010). Pemasaran dengan memanfaatkan media sosial ternyata dipandang lebih penting bagi UKM dari pada perusahaan besar karena kurangnya sumber daya UKM dalam pemasaran produk dan jasa, terutama pada skala global (Virtanen, Bjork, \& Sjostrom, 2017). Selain itu penelitian yang dilakukan oleh Suryana, dkk menyatakan bahwa salah satu faktor yang mempengaruhi kinerja UKM adalah strategi komunikasi pemasaran (Suryana, Zein, Sumartias, \& Gemiharto, 2019).

Instagram merupakan salah satu media sosial yang paling populer sekarang ini dan banyak digunakan oleh masyarakat. Hasil survei dari Hoosuite (2019) terhadap media sosial yang ada, menunjukkan bahwa Instagram merupakan media sosial yang terbanyak digunakan setelah YouTube dan Facebook, yaitu sekitar 62 juta jiwa penduduk Indonesia adalah pengguna aktif Instagram (Kemp \& Simon, 2019).

Instagram telah menjadi platform pemasaran yang sangat populer di antara perusahaan tidak hanya karena jumlah penggunanya yang semakin banyak, tetapi karena karakteristiknya, menggaris bawahi trend konten dalam pemasaran media sosial (Virtanen et al., 2017) Instagram memiliki potensi bagi perusahaan atau pelaku UKM yang 
ingin memperluas portofolio brand mereka secara online (Murphy, 2014).

Dalam menciptakan dan meningkatkan kesadaran akan brand dan produk salah satunya adalah mengisi media sosial perusahaan dengan konten (Virtanen et al., 2017). Bagi UKM, Instagram sangat membantu pemasaran dan menciptakan hubungan dengan konsumen. Gambar dan konten visual Instagram dapat efektif dalam membangun kesadaran, meningkatkan lalu lintas percakapan, berbagi, menyebar dan menghasilkan minat pada penawaran yang sangat visual.

Survei yang dilakukan oleh Instagram melalui perusahaan riset pasar yang berbasis di Prancis yaitu Ipsos pada tahun 2018 menyatakan bahwa Instagram memiliki dampak yang besar bagi UKM di Indonesia, karena dengan berbagi gambar tersebut membawa konsumen lebih dekat terhadap hal-hal yang mereka sukai. Dari UKM yang mereka survei, 66\% meyakini bahwa Instagram bisa mendatangkan pelanggan dari dalam dan luar negeri, 87\% UKM juga meyakini bahwa dari Instagram meningkatkan penjualan mereka. Sementara itu. survei yang dilakukan pada pengguna Instagram secara personal menunjukkan bahwa $81 \%$ responden memanfaatkan platform Instagram untuk menggali informasi lebih dalam mengenai suatu produk, dan $66 \%$ melakukan pembelian pada produk di Instagram.
Dalam berbelanja online, survei yang dilakukan oleh IDN Research Institute bekerjasama dengan Alvara Research Center yang melibatkan 1400-an responden di 12 kota, tentang Indonesia Millenial Report 2019 menunjukkan hasil menarik. Di antara beragam kebutuhan manusia, ternyata produk yang paling banyak dibeli dalam enam bulan terakhir adalah produk pakaian/germen yaitu 24,6 \%.

Konten yang paling disukai oleh pelanggan Indonesia adalah konten yang berkaitan dengan fashion dan aksesoris. Terdapat 44\% pengguna Instagram menyukai konten ini (Parikesit \& Anggit, 2016). Media sosial Instagram diharapkan dapat menjangkau lebih luas pasar dan konsumen, agar lebih mengenal produk dan usaha yang dijalani UKM. Bagi UKM fashion hal ini menjadi media pemasaran bagi mereka kepada para konsumen agar produk-produk mereka dikenal oleh masyarakat luas.

Sejak dulu Kota Bandung dikenal sebagai kota mode. Di kota ini tersedia banyak pilihan bagi orang-orang yang ingin berbusana, dari yang berkelas sampai jenis pakaian kodian. Dari dulu pula Kota Bandung sudah menjadi tujuan wisata belanja fashion. Banyak produk fahion lahir di Kota ini. Salah satunya adalah brand Madre. Madre merupakan produsen jaket parka. Melihat tren fashion anak muda yang menyukai fashion ala Eropa dan Korea, jaket kini mulai berubah fungsi bukan hanya sebagai alat untuk 
melindungi dari udara dingin. Pengguna jaket dianggap memiliki nilai ego tersendiri ketika memakainya. Tiap hari bisa berganti jaket sesuai dengan tampilan yang diinginkan pada hari tersebut. Hal ini yang menjadi pertimbangan munculnya brand Madre ini.

Madre melakukan strategi komunikasi pemasaran dengan menggunakan Instagram. UKM ini menjadi dikenal karena aktif dalam memasarkan brand-nya lewat media sosial tersebut. Dalam hal ini, Instagram menjadi media pemasaran bagi brand Madre. Madre menggabungkan dua bentuk komunikasi media sosial yaitu firm-created content dan usergenerated content. Melaluinya, Madre ingin dipandang sebagai produsen jaket parka yang fashionable.

Madre sendiri dirintis pada tahun 2014 dan tahun 2015 mulai mempromosikan produknya melalui Instagram. Saat itu brand ini hanya memiliki beberapa follower saja, dengan melakukan promosi yang intens pada media sosial Instagram sehingga sekarang brand ini telah memiliki 9.000 follower dengan akun Instagram yaitu@madre_parka.Follower-nya telah tersebar dari berbagai wilayah Indonesia, tidak hanya pada masyarakat Kota Bandung saja. Pemanfaatan Instagram ini dianggap memberikan efek pada peningkatan penjualan secara online. Sebelum memanfaatkan Instagram konsumen sangat terbatas, berasal dari Kota Bandung, sekarang konsumen berasal dari beberapa kota di Indonesia, seperti Kalimantan, Malang, Jakarta, Bogor, Bali, dan Batam.

Promosi dengan memanfaatkan Instagram bagi Madre menimbulkan minat beli masyarakat terhadap produk-produk dari Madre. Selain itu juga dirasakan menambah keyakinan konsumen terhadap brand Madre itu sendiri.

UKM perlu mengetahui bagaimana menjalin komunikasi melalui media sosial dalam membangun brand equity, brand attitude serta minat beli konsumen terhadap produk dengan memberikan konten yang tepat pada media sosial sebagai media pemasaran. Instagram memiliki potensi terbuka bagi UKM yang ingin memperluas portofolio online brand mereka. Pada Instagram, trend konten yang dihasilkan oleh konsumen yang diedarkan kepada konsumen lainnya (user-generated content), sama pentingnya dengan konten yang dibuat oleh perusahaan sendiri (firm-created content). Oleh sebab itu, penelitian ini akan menelaah bagaimana konten yang dibuat oleh perusahaan (firm-created content) dan konten yang dibuat oleh pengguna (user-generated content) dalam mempengaruhi brand equity dan brand attitude yang berujung pada bagaimana purchase intention konsumen Madre.

Deddy Mulyana mendefinisikan bahwa "komunikasi dianggap sebagai tindakan 
yang disengaja (intentional act) untuk menyampaikan pesan demi memenuhi kebutuhan komunikator" (Mulyana, 2012). Sementara itu, pemasaran merupakan sebuah fungsi organisasi dan serangkaian proses untuk menciptakan, mengomunikasikan, dan memberikan nilai kepada pelanggan, dan untuk mengelola hubungan pelanggan dengan cara yang menguntungkan bagi organisasi dan pemangku kepentingan (Kotler \& Keller, 2012; Kotler \& Armstrong, 2004).

Komunikasi pemasaran adalah sarana yang digunakan perusahaan dalam upaya untuk menginformasikan, membujuk, dan mengingatkan konsumen baik secara langsung ataupun tidak langsung tentang produk atau jasa yang dijual (Kotler \& Armstrong, 2004). Komunikasi pemasaran memegang peranan penting dalam memasarkan suatu produk, yang memiliki kemampuan untuk menggugah minat orang banyak agar tergerak untuk membeli. Tidak dapat terelakkan bahwa komunikasi pemasaran mempengaruhi kinerja Usaha Kecil dan Menengah (Suryana et al., 2019).

Dalam pengimplementasiannya, AIDA merupakan alat penyampaian suatu pesan yang ideal kepada konsumen. AIDA merupakan strategi yang melalui tahap perhatian (attention), ketertarikan (interest), minat (desire), dan mengambil tindakan (action) (Kotler \& Keller, 2012).
Pemasaran menggunakan media sosial memungkinkan perusahaan untuk mencapai sebuah pemahaman yang lebih baik tetang kebutuhan pelanggan untuk membangun hubungan yang efektif (Srinivasan, Bajaj, \& Bhaton, 2016). Media sosial telah menyebabkan perubahan signifikan dalam strategi dan alatyang digunakan perusahaan dalam berkomunikasi dengan pelanggan (Srinivasan, Bajaj, \& Bhaton, 2016). Menurut Godes \& Mayzlin (2009) untuk memeriksa dampak dari komunikasi brand pada media sosial, maka dapat dibedakan menjadi dua bentuk yaitu: a) firm-created content, dan b) komunikasi media sosial user-generated content (Godes \& Mayzlin, 2009; Schivinski \& Dabrowski, 2015).

Firm-created content (FCC) adalah komunikasi di bawah kendali suatu brand apakah itu perwakilan dari brand itu sendiri atau dari pemasar (Bruhn et al., 2012). Firmcreated content (FCC) membantu perusahaan untuk membuat, memelihara, dan memperkuat hubungan mereka dengan target konsumen mereka (Poulis et al., 2018).

User generated content (UGC) adalah komunikasi yang dibuat langsung oleh pengguna (Poulis et al., 2018). UGC tidak dibuat oleh orang-orang pemasaran dari perusahaan tetapi oleh masyarakat umum (Bashir et al., 2017). UGC adalah kendaraan yang berkembang pesat untuk percakapan merek dan wawasan 
konsumen (Christodoulides, Jevons, \& kesimpulan bahwa dia pasti akan pergi dengan

Bonhomme, 2012).

User-generated content melibatkan berbagai topik, termasuk brand dan produk, perusahaan tidak lagi menajadi sumber utama dalam komunikasi brand (Berthon, Pit, \& Campbell, 2008). Selain itu UGC cenderung menganjurkan merek, berbagi opini tentang merek dan produk kepada konsumen lain (Daugherty, Eastin, \& Bright, 2008).

Konsepsi brand equity adalah aset utama pemasaran yang dapat menghasilkan hubungan yang membedakan ikatan antara perusahaan dan publik dan memelihara perilaku pembelian jangka panjang (Schivinski \& Dabrowski, 2014). Brand equity adalah pengaruh diferensial positif apabila pelanggan mengenal nama sebuah brand, ia kemungkinan akan merespon produk atau jasa tersebut (Kotler, 2008).

Brand attitude sering dikonseptualisasikan sebagai evaluasi global yang didasarkan pada reaksi yang menguntungkan atau tidak menguntungkan terhadap rangsangan atau kepercayaan terkait merek (Murphy, 2014). Kekuatan brand attitude memprediksi perilaku yang menarik bagi perusahaan, termasuk pertimbangan merek, niat beli, perilaku pembelian dan pilihan merek (Priester, Nayakankuppam, Fleming, \& Godel, 2004).

Purchase intention didefinisikan sebagai momen ketika konsumen telah mencapai produk tertentu (Yan, 2011). Niat beli paling baik digambarkan sebagai penggabungan antara minat dan tindakan (Kim \& Ko, 2012).

Dengan kata lain, purchase intention adalah kecendrungan tindakan pribadi terhadap merek, sedangkan sikap adalah evaluasi keseluruhan (Chen, Ching, \& Tsai, 2008). Purchase intention menjelaskan langkah akhir dari proses pembelian, di mana konsumen tiba pada niat untuk membeli produk merek tertentu (Growel, Monroe, \& Krishnan, 1998).

Melalui komunikasi bermedia sosial, manajer pemasaran cenderung tetap terhubung dengan konsumen setia mereka (Bashir et al., 2017). Komunikasi merek secara positif mempengaruhi brand equity selama pesan tersebut menciptakan reaksi konsumen yang puas terhadap produk yang dimaksud dibandingkan dengan produk serupa yang tidak bermerek (Yoo, Donthu, \& Lee, 2000). Perusahaan harus melihat media sosial sebagai komponen penting dari bauran pemasaran, dan mengintegrasikannya dalam komunikasi pemasaran mereka untuk meningkatkan brand equity (Bruhn et al., 2012). Firm-created content media sosial yang berdampak pada elemen konsumen berbasis brand equity (Schivinski \& Dabrowski, 2014). Selain itu, rangsangan komunikasi menyebabkan efek positif pada konsumen sebagai penerima. 
Komunikasi secara positif mempengaruhi kesadaran individu akan sebuah merek (Bruhn et al., 2012). Konten konstruktif firm-generated content media sosial memiliki dampak positif pada brand equity (Smith, Fischer, \& Yongjian, 2012).

Keterlibatan UGC dapat dianggap sebagai bentuk keterlibatan dengan produk dan merek karena UGC yang terkait dengan merek adalah kegiatan yang terkait dengan konsumsi (Muntinga, Smit, \& Moorman, 2012). UGC dianggap sebagai alat yang meningkat dengan cepat untuk mendapatkan wawasan konsumen (Bashir et al., 2017). UGC membawa informasi tentang produk/ brand yang dapat berguna bagi pelanggan dalam hal consumen based on brand equity (CBBE) (Schivinski \& Dabrowski, 2014).

Aktivitas media yang dihasilkan oleh konsumenataukomunitasyang tidak dibayaratau diinduksi oleh pemilik merek diklaim memiliki dampak pada perubahan yang berpotensi pada kamunikasi dan merek (Murphy, 2014). Firmcreated content dapat mempengaruhi sikap dan perilaku pelanggan secara signifikan (Kumar, Bezawada, Rishika, R.Janakiranam, \& Kannan, 2016). Fakta bahwa firm-created content atau media tradisional dalam bentuk iklan sebagian besar digunakan untuk menciptakan sikap positif (Murphy, 2014).

User-generated content memiliki implikasi yang penting bagi pemasaran (Schivinski \& Dabrowski, 2014). Konsumen yang terlibat dengan user-generated content cendrung menjadi penganjur merek, berbagi pendapat tentang merek dan produk dengan konsumen lain (Daugherty et al., 2008). Selain itu usergenerated content dianggap oleh konsumen sesuatu yang dapat dipercaya (Christodoulides et al., 2012). User-generated content dapat membuat penggambaran positif atau negatif dari suatu merek, yang pada gilirannya dapat berdampak pada sikap konsumen terhadap merek tersebut (Murphy, 2014).

Tingkat brand equity yang tinggi mendorong pembelian permanen untuk merek yang sama (Yoo et al., 2000). Adanya pengaruh positif brand equity pada preferensi konsumen dan purchase intention (Walgrem, Ruble, \& Donthu, 1995).

Brand attitude adalah penentu utama purchase intention (Abzari, Ghassemi, \& Vosta, 2014). Brand attitude memiliki pengaruh kuat pada purchase intention, karena brand attitude dianggap sebagai indikator yang baik untuk niat perilaku (Wang, 2009). Purchase intention muncul sebagai akibat dari sikap yang dibentuk terhadap merek tertentu (Pradhana, Duraipandiana, \& Sethib, 2014). Brand attitude menyebabkan dampak yang lebih besar pada purchase intention karena motivasi konsumen meningkat (Mackenzie \& Spreng., 1992). 


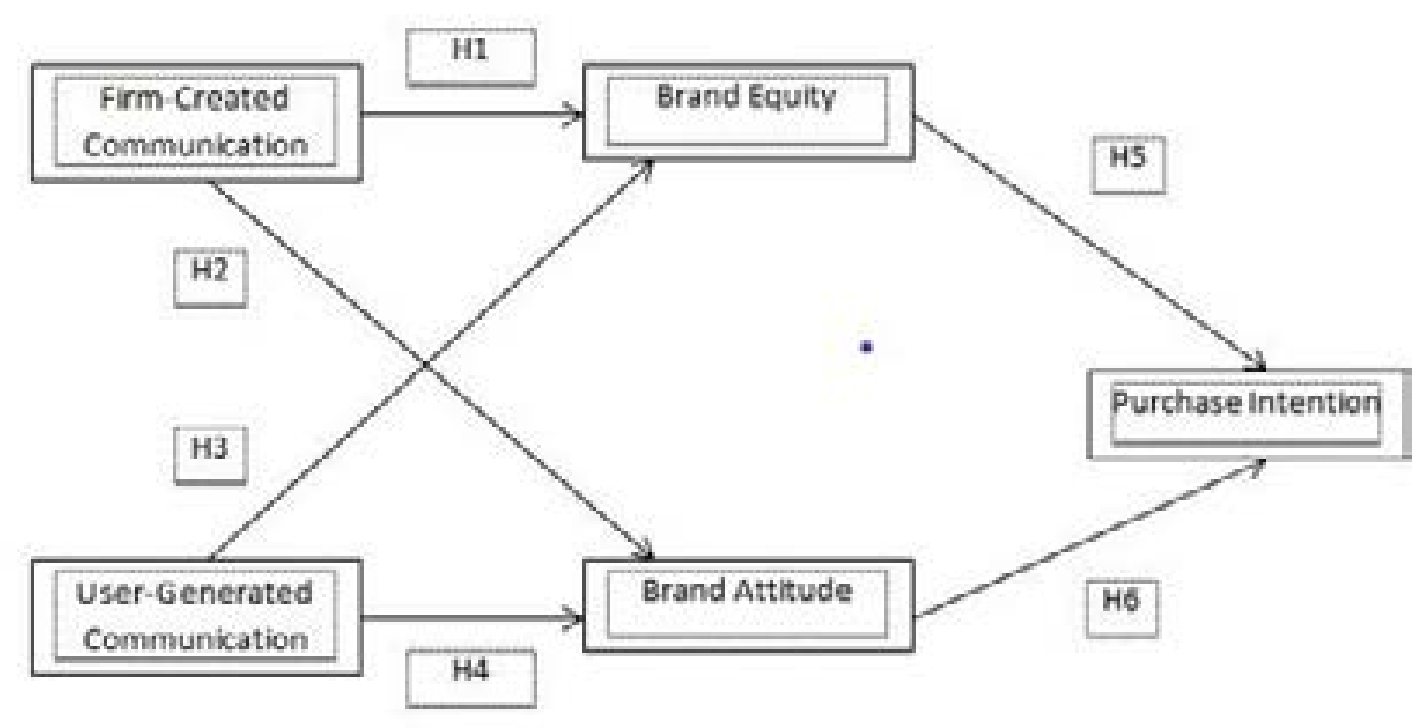

Sumber : Adaptasi dari Penelitian (Schivinski \& Dabrowski, 2015)

\section{Gambar 1 Kerangka Penelitian}

Purchase intention adalah kecenderungan tindakan pribadi terhadap merek, sedangkan attitude adalah evaluasi keseluruhan (Chen et al., 2008). Berdasarkan uraian diatas maka, untuk kerangka penelitian dapat dilihat pada Gambar 1.

Berdasarkan latar belakang yang telah dipaparkan, maka penelitian ini bertujuan untuk mengetahui pengaruh dari komunikasi media sosial Instagram (firm-created content dan user-generated content) terhadap brand equity, brand attitude dan purchase intention pada konsumen Madre.

\section{METODE PENELITIAN}

Artikel ilmiah ini ditulis dari hasil penelitian eksplanatori. Penelitian eksplanatori dilakukan untuk memperoleh pengertian mengenai fenomena yang diteliti sebagai sebuah cara untuk melengkapi pengetahuan melalui pengembangan teori secara lebih lanjut. Didalamnya dilakukan serangkaian pengujian hipotesis (Sekaran \& Bougie, 2013). Analisis dalam penelitian dilakukan dengan menggunakan pendekatan kuantitatif dengan metode survei. Dalam pengumpulan data, digunakan kuesioner sebagai alat instrumen utama dalam mengumpulkan data. Kuesioner dibuat dalam google form dan kemudian disebarkan secara online kepada follower 
akun Instagram@madre_parka. Penyebaran kuesioner dilakukan secara acak kepada follower Instagram @madre_parka dengan melakukan chatting melalui direct massage (DM) agar mereka bersedia untuk mengisi kusioner penelitian.

Pada penelitian ini yang menjadi populasi adalah seluruhfollowers dari akun Instagram @ madre_parka yaitu sebanyak 9.827 followers. Ukuran sampel adalah jumlah indikator dikali 5 sampai 10 (Hair, Black, Babin, \& Anderson, 2014). Pada penelitian ini, terdiri atas 26 indikator, maka $26 \times 5=130,26 \times 10=260$. Maka jumlah sampel 130-260, pada penelitian ini jumlah sampel yaitu 208 respnden.

Pemilihan sampel penelitian ini dikerjakan dengan memanfaatkan teknik purposive sampling. Pengambilan sampelnya dengan menentukan karakter tertentu atau dengan atau ciri-ciri khusus. Kharakteristik khusus tersebut harus memiliki hubungan yang erat dengan kriteria atau ciri-ciri populasi yaitu mereka yang mau mengisi kusioner secara online dan memenuhi syarat dari sampel yang ditetapkan peneliti yaitu: mereka yang berusia 18-41 tahun, merupakan follower akun Instagram @ madre_parka serta bukan reseller dan pengguna aktif Instagram.

Analisis data dilakukan dengan menggunakan model multivariat teknik Structural Equation Modeling (SEM).
Perangkat lunak yang digunakan adalah IBM SPSS AMOS

Structural Equation Modeling (SEM) adalah suatu teknik analisis multivariate generasi kedua. Ia menggabungkan analisis faktor (factor analysis) dan analisis jalur (path analysis). SEM memungkinkan peneliti dapat menguji, dan secara simultan mengestimasi hubungan antara multiple laten variabel dengan multiple laten variabel dependen (Latan, 2013).

\section{HASIL DAN PEMBAHASAN}

Dengan menggunakan analisis SEM, pada uji measurement model didapat hasil Chi-square sebesar 530.959, dengan degree of freedom yaitu sebesar 292 dan untuk probability level yaitu sebesar 0,000. Maka uji terhadap hipotesis model menunjukkan bahwa model telah sesuai dengan data (atau disebut fit) terhadap data yang digunakan pada penelitian ini. Meskipun nilai chi-sqaure cukup besar, namun nilai chisquare terpengaruh oleh nilai degree of freedom. Apabila nilai degree of freedom kecil maka nilai chi-square akan berkurang.

Uji model struktural dalam penelitian ini dapat dilihat pada gambar 2 , yang menunjukkan bahwa model memenuhi kriteria fit. Pada Tabel 1 di bawah ini dapat dilihat bahwa model telah baik karena semua kriteria goodness of fit index secara keseluruhan sudah masuk dalam kategori baik. Meski pada uji chi-square pada full model diperoleh nilai sebesar 530,959 yang artinya belum memenuhi persyaratan disyaratkan 




Sumber : Data Primer diolah 2020

\section{Gambar 2 Uji Structural Equation Model}

dimana pada evaluasi model menunjukkan marginal, tetapi nilai ini dapat diterima. Dengan demikian dapat melakukan analisis selanjutnya dengan melihat nilai CMIN/DF, RMSEA dan CFI yang telah memenuhi kriteria baik, maka dapat dilakukan analisis selanjutnya.

Pengujian hipotesis didasarkan atas pengolahan datapenelitiandenganmenggunakan analisis SEM, dengan cara menganalisis nilai regresi. Adapun menganalisis lebih jelas mengenai pengaruh strategi komunikasi media sosial Instagram (firm-created content dan user-generated content) terhadap brand equity, brand attitude dan purchase intention yang ditampilkan pada Tabel 2.

Pengujian hipotesis dilakukan melalui analisis nilai Critical Ration (CR) dan nilai Probability $(\mathrm{P})$ terhadap data yang diolah, di mana untuk masing-masing koefesien yang diisyaratkan $\mathrm{CR}>1,96$ dan $\mathrm{P}<0,05$. Jika hasil pengolahan menunjukkan nilai yang memenuhi kriteria itu, maka hipotesis pada penelitian ini dapat diterima. Dengan terperinci, pengujian hipotesis penelitian dibahas secara bertahap 
Tabel 1 Hasil Uji Full Model

\begin{tabular}{|l|l|l|l|}
\hline $\begin{array}{c}\text { Goodness } \\
\text { of } \\
\text { Fit Indeks }\end{array}$ & \multicolumn{1}{|c|}{$\begin{array}{c}\text { Cut of } \\
\text { Value }\end{array}$} & \multicolumn{1}{|c|}{$\begin{array}{c}\text { Hasil } \\
\text { Analisis }\end{array}$} & $\begin{array}{c}\text { Evaluasi } \\
\text { Model }\end{array}$ \\
\hline Chi Square & $\leq 332,854$ & 530,959 & Marginal \\
Probability & $\geq 0,05$ & 0,000 & Marginal \\
RMSEA & $\leq 0,08$ & 0,063 & Baik \\
CMIN/DF & $\leq 2,00$ & 1,818 & Baik \\
GFI & $\geq 0,90$ & 0,844 & Marginal \\
AGFI & $\geq 0,90$ & 0,812 & Marginal \\
CFI & $\geq 0,90$ & 0,957 & Baik \\
TLI & $\geq 0,90$ & 0,952 & Baik \\
NFI & $\geq 0,90$ & 0,910 & Baik \\
IFI & $\geq 0,90$ & 0,958 & Baik \\
\hline
\end{tabular}

Sumber: Data Primer diolah 2020

sesuai hipotesis yang diajukan dalam penelitian. Dari Tabel 2 di bawah ini dapat kita lihat bagaimana hubungan masing-masing variabel.

Pada tabel 2 tersebut parameter estimasi hubungan antara firm-created content terhadap brand equity. Firm-created content berpengaruh signifikan terhadap brand equity karena nilai CR (t hitung) sebesar 2,402 dimana nilai ini lebih

\section{Tabel 2 Regression Weights}

\begin{tabular}{|l|c|c|c|c|c|c|l|}
\hline & & & $\begin{array}{c}\text { Esti- } \\
\text { mate }\end{array}$ & S.E. & C.R & P & Label \\
\hline BE & $\leftarrow$ & FCC & .461 & .192 & 2.402 & .016 & par_22 \\
\hline BA & $\leftarrow$ & FCC & .510 & .222 & 2.301 & .021 & par_23 \\
\hline BE & $\leftarrow$ & UGC & .621 & .174 & 3.563 & $* * *$ & par_24 \\
\hline BA & $\leftarrow$ & UGC & .438 & .198 & 2.219 & .027 & par_25 \\
\hline PI & $\leftarrow$ & BE & .415 & .091 & 4.567 & $* * *$ & par_26 \\
\hline PI & $\leftarrow$ & BA & .517 & .101 & $5.142 \backslash$ & $* * *$ & par_27 \\
\hline
\end{tabular}

Sumber : Data Primer diolah 2020 besar dari t tabel yaitu 1,96 sedangkan untuk nilai $\mathrm{p}$ value sebesar 0,016 atau lebih kecil dari 0,05 . Kesimpulan yang dapat diambil mengenai hipotesis 1, menyatakan bahwa firm-created content berpengaruh signifikan terhadap brand equity dapat diterima. Firm-created content berpengaruh positif terhadap brand equity. Dengan begitu semakin bagus firm-created content Instagram Madre maka akan semakin meningkat brand equity terhadap merek.

Berdasarkan pengujian hipotesis yang dilakukan terbukti bahwa ada pengaruh positif dan signifikan antara firm-created content terhadap brand equity. Hal ini sejalan dengan penelitian yang dilakukan oleh (Smith, Fischer, \& Yongjian, 2012) bahwa firm-created content media sosial berpengaruh positif terhadap brand equity. Oleh karena itu, perusahaan atau pelaku UKM harus menjadikan firmcreated content sebagai komponen penting dalam meningkatkan brand equity (Bruhn, Schoenmueller, \& Schafer, 2012). Firmcreated content membantu perusahaan atau pelaku UKM untuk membuat, memelihara dan memperkuat hubungan mereka dengan target konsumen mereka sehingga meningkatkan kesadaran, kepercayaan dan loyalitas terhadap merek tersebut. Maka seamkin bagus dan menarik firm-created content yang dibuat oleh suatu brand akan semakin meningkatkan brand equity follower terhadap brand tersebut (Poulis 
et al., 2018).

Pada pengujian hipotesis 2 yaitu pengaruh user-generated content terhadap brand equity didapatkan nilai CR (t hitung) sebesar 3,563 di mana nilai ini lebih besar dari t tabel yaitu 1,96 dan untuk nilai $p$ value 0,00 yang jauh lebih kecil dari 0,05. Sehingga hipotesis 2 diterima. Kesimpulannya adalah user-generated content berpengeruh positif dan signifikan terhadap brand equity. Untuk itu semakin menarik user-generated content maka semakin besar pengaruhnya terhadap brand equity konsumen terhadap produk Madre.

Hasil pengujian hipotesis 2 pada penelitian ini, ditemukan bahwa user-generated content berpengaruh positif dan signifikan terhadap brand equity. Sejalan dengan penelitian (Schivinski \& Dabrowski, 2014) bahwa usergenerated content berpengaruh positif terhadap brand equity. User-generated content biasanya berisi informasi tentang produk atau merek yang dapat sangat berguna bagi pelanggan dalam hal membangun brand equity. User-generated content merupakan sumber informasi yang lebih andal dibandingkan dengan konten yang diterbitkan melalui saluran tradisional seperti iklan yang dibuat oleh perusahaan (Morra, Ceruti, Chierinci, \& Gregorio, 2018) sehingga meningkatkan kepercayaan konsumen. Usergenerated content melibatkan berbagai topik baik pendapat terhadap suatu brand atau produk, bisa juga berupa anjuran serta opini tentang brand dan produk dari satu konsumen kepada konsumen lainnya (Berthon et al., 2008). Usergenerated content sangat berpengaruh terhadap brand equity, user-generated content yang positif tentang suatu brand akan berdampak positif juga pada kesadaran, loyalitas terhadap suatu brand atau produk. Semakin bagus dan menarik user-generated content suatu brand pada media sosial akan semakin meningkatkan brand equity follower mereka terhadap brand tersebut.

Pengujian pada hipotesis 3 yaitu pengaruh firm-created content terhadap brand attitude didapatkan nilai CR (t hitung) sebesar 2,301 dimana nilai ini lebih besar dari 1,96 dan $\mathrm{p}$ value sebesar 0,021 atau lebih kecil dari 0,05. Ini menunjukkan hipotesis 3 diterima, yakni firm-created content berpengaruh signifikan terhadap brand attitude pada konsumen Madre. Hubungan antar kedua variabel positif, yang artinya semakin bagus firm-created content Instagram Madre maka akan semakin besar pengaruhnya terhadap brand attitude konsumen.

Hasil pengujian hipotesis 3 pada penelitian ini, ditemukan bahwa firm-created content berpengaruhpositifdansignifikanterhadapbrand attitude sejalan dengan penelitian (Schivinski \& Dabrowski, 2014) menyatakan bahwa firmcreated content media sosial memiliki pengaruh positif terhadap brand attitude. Firm-created 
content digunakan untuk menciptakan sikap positif terhadap brand (Murphy, 2014). Selain itu Firm-created content dapat mempengaruhi sikap dan perilaku pelanggan secara signifikan (Kumar et al., 2016). Brand attitude sering dikonseptualisasikan sebagai evaluasi global yang didasari pada reaksi yang menguntungkan atau tidak menguntungkan terhadap rangsangan atau kepercayaan terkait brand (Murphy, 2014), untuk itu bagaimana menciptakan kepercayaan follower terhadap postingan dan komunikasi yang dibentuk oleh perusahaan atau pelaku UKM.

Parameter pengujian pada variabel usergenerated content terhadap brand attitude memiliki nilai CR (t hitung) yaitu 2,219 dimana nilai ini lebih besara dari $\mathrm{t}$ tabel $=1,96$ sedangkan untuk $p$ value nya sebesar 0,027 atau lebih kecil dari 0,05 . Sehingga hipotesis 4 diterima, karena telah memenuhi syarat hipotesis diterima. Untuk itu dapat disimpulkan mengenai hipotesis 4 yang menyatakan bahwa user-generated content berpengaruh positif dan signifikan terhadap brand attitude. Usergenerated content yang positif tentang Madre di Instagram akan meningkatkan brand attitude positif pada follower Madre.

Hasil pengujian hipotesis 4 pada penelitian ini, ditemukan bahwa user-generated conten berpengaruh positif dan signifikan terhadap brand attitude, hal ini sejalan dengan peneltian
(Schivinski \& Dabrowski, 2014) menyatakan bahwa user-generated content memiliki efek positif terhadap brand attitude. User-generated content dapat membuat penggambaran positif atau negatif dari suatu brand, di mana nantinya dapat berdampak pada sikap konsumen terhadap brand tersebut (Murphy, 2014). Dengan demikian, semakin bagus dan menarik user-generated content suatu brand akan meningkatkan sikap positf follower terhadap brand tersebut.

Dari pengolahan data pada software AMOS yang ditampilkan pada Tabel 2, dimana pada variabel brand equity terhadap purchase intention memiliki nilai CR (t hitung) yaitu sebesar 4,567 dimana nilai ini lebih besar dari t tabel yaitu 1,96 dan untuk nilai $p$ value sebesar 0,000 jauh lebih kecil dari 0,05. Sehingga hipotesis 5 diterima, dikarenakan hasil telah memenuhi syarat yang ditentukan. Kesimpulanya adalah brand equity berpengaruh positif dan signifikan terhadap purchase intention.

Pada penelitian ini ditemukan bahwa Brand equity memiliki pengaruh positif dan signifikan terhadap purchase intention, hal ini sejalan dengan peneltian yang dilakukan oleh (Schivinski \& Dabrowski, 2014) menyatakan bahwa brand equity memiliki pengaruh positif terhadap purchase intention. Tingkat brand equity yang tinggi dapat mendorong pembelian 
permanen untuk brand yang sama (Yoo et al., 2000). Semakin tinggi brand equity suatu brand maka semakin tinggi purchase intention follower dari brand tersebut.

Parameter pengujian pada variabel brand attitude terhadap purchase intention memiliki nilai CR (t hitung) yaitu sebesar 5,142 dimana nilai ini lebih besar dari $\mathrm{t}$ tabel yaitu 1,96 dan untuk nilai $\mathrm{p}$ value sebesar 0,000 dimana jauh lebih kecil dari 0,05. Sehingga hipotesis 6 diterima, dikarenakan hasil telah memenuhi syarat yang ditentukan. Kesimpulanya adalah brand attitude berpengaruh positif dan signifikan terhadap purchase intention. Semakin tinggi brand attitude follower Madre akan meningkatkan purchase intention follower terhadap produk Madre.

Hasil pengujian hipotesis 6 pada penelitian ini, ditemukan bahwa brand attitude berpengaruh positif dan signifikan terhadap purchase intention, hal ini sejalan dengan apa yang diteliti oleh (Schivinski \& Dabrowski, 2014) menyatakan bahwa brand attitude memiliki pengaruh positif terhadap purchase intention. Sikap pelanggan terhadap suatu brand memiliki pengaruh yang kuat terhadap purchase intention karena sikap merupakan penentu yang cocok untuk niat pembelian. Purchase intention muncul sebagai akibat dari sikap yang dibentuk terhadap suatu brand (Pradhana et al., 2014) Brand attitude akan meningkatkan motivasi seseorang sehingga timbulnya purchase intention terhadap suatu brand. Adanya persepsi konsumen yang lebih positif tentang keunggulan-keunggulan sebuah brand akan berkaitan dengan niat beli yang juga akan menjadi lebih kuat (Schivinski \& Dabrowski, 2014). Semakin tinggi brand attitude suatu brand maka akan semakin meningkat purchase intention follower terhadap brand tersebut.

Dengan melihat hasil analisis pada Tabel 2 dapat dipahami bahwa pengaruh yang paling besar adalah variabel user-generated content terhadap brand equity. Karena user-generated content berkaitan dengan bagaimana pendapat orang-orang terhadap brand tersebut. Selain itu user-generated content menjadi sumber informasi yang lebih akurat dan terpercaya, karena bersumber dari konsumen yang telah memiliki pengalaman dengan produk tersebut, baik itu sebagai pembeli maupun sebagai pengguna. Ia menjadi acuan dan rekomendasi bagi follower yang ingin membeli produk pada brand tersebut.

\section{SIMPULAN}

Penelitian ini berhasil memperlihatkan bahwasanya komunikasi yang dilakukan melalui media sosial baik firm-created content maupun user-generated content memiliki pengaruh positif dan signifikan terhadap brand equity, brand attitude, dan purchase intention. 
Firm-created content memiliki pengaruh postif dan signifikan terhadap brand equity. Responden yang merupakan follower dari akun Instagram Madre merasakan bahwa konten yang telah diberikan oleh Madre menjadi nilai tambah terhadap brand equity mereka. Konten-konten yang dibuat oleh Madre semakin mengenalkan Madre kepada follower nya dan memilih Madre sebagai penyedia jaket dan parka bagi mereka. User-generated content memiliki pengaruh postif dan signifikan terhadap brand equity. Keberadaan user-generated content (testimoni) dari konsumen Madre yang di bagikan melalui Instagram, menjadi nilai tambah bagi follower dalam meningkatkan brand equity konsumen terhadap brand Madre.

Firm-created content memiliki pengaruh positif dan signifikan terhadap brand attitude. Konten yang disampaikan oleh Madre (firmcreated content) pada Instagram akan menjadi media informasi utama bagi mereka bagaimana produk yang ditawarkan oleh Madre, sehingga menimbulkan sikap positif (brand attitude) mereka terhadap brand Madre.

Brand equity memiliki pengaruh positif dan signifikan terhadap purchase intention. Ketika suatu brand memiliki brand equity yang tinggi dari para konsumen atau pelanggan nya sehingga akan meningkatkan niat pembelian (purchase intention) terhadap suatu produk.

Brand attitude memiliki pengaruh positif dan signifikan terhadap purchase intention. Madre telah membangun brand attitude positif follower nya sehingga menimbulkan niat mereka untuk membeli (purchase intention). Tinginya sikap positif dari follower tentang Madre sehingga meningkatkan niat beli mereka terhadap produk yang ditawarkan oleh Madre (purchase intention).

Adapun beberapa saran terkait penelitian ini agar dapat menjadi masukan bagi pengembangan penelitian dimasa yang akan datang adalah dengan memperluas penelitian tidak hanya pengaruh firm-created content dan user generated content, tapi dapat menambahkan variabel eWOM dan Endorsement serta memperluas objek penelitian tidak hanya pada satu UKM saja tetapi bisa beberapa UKM sebagai pembanding, dan bisa juga dengan media sosial yang berbeda seperti Instagram dengan Facebook. Selain itu untuk responden bisa mengambil kelompok responden seperti pada segmentasi generasi $\mathrm{X}, \mathrm{Y}$ dan $\mathrm{Z}$.

\section{DAFTAR PUSTAKA}

Abzari, M., Ghassemi, R. A., \& Vosta, L. N. (2014). Analysing the effect of social media on brand attitude and purchase intention: the case of Iran Khodro Company. Social and Behavioral Sciences, 143, 822-826.

Barlow, M. M. (2015). Use and measurement of social media for smes. Journal of Small Business and Enterprise Development, 22. Bashir, M. A., Ayub, N., \& Jalees, T. (2017). 
The impact of the firm generated contents and the user generated contents throuhg social media on brand elements. Pakistan Business Review, 744-760.

Berthon, P., Pit, L., \& Campbell, C. (2008). Ad lib: when customers created the ad. California Management Reviews, 5(4), 6-30.

Bruhn, M., Schoenmueller, V., \& Schafer, D. B. (2012). Are social media replacing traditional media in terms of brand equity creation? Management Research Reviews, 35(9), 770-790.

Chen, J. S., Ching, R., \& Tsai, H. T. (2008). Blog effect on brand attitude and purchase intention. IEEE.

Christodoulides, G., Jevons, C., \& Bonhomme, J. (2012). Memo to marketers: quantitative evidence for change. How user-generated content really affects brands. Journal of Advertisng Research.

Daugherty, T., Eastin, M. S., \& Bright, L. (2008). Exploring consumer motivations for creating user-generated content. Journal of Interactive Advertising, 8(2), 16-25.

Godes, D., \& Mayzlin, D. (2009). Firm- created word-of-mouth communication : evidence from a field test. Marketing Sciences, 29(4), 721-739.

Growel, D., Monroe, K. B., \& Krishnan, R. (1998). The effect of price-comparison advertising on buyer's perceptions of acquicition value, transaction value, and behavioral intention. Journal of Marketing, $62,46-59$.

Hair, J. F., Black, W. C., Babin, B. J., \& Anderson, R. E. (2014). Multivariate data analysis (seventh edition). Canada: Pearson.

Kaplan, A., \& Haeniein, M. (2010). Users of the world, united! The challenges and opportunities of social media. Business Horizon, 53, 59-68.

Kemp, \& Simon. (2019). Digital 2019: Indonesia. Retrieved from Dare Portal website: https://datareportal.com

Kim, A. J., \& Ko, E. (2012). Do social media marketing activities enchanceconsumer equity? An empiris study of luxury fashion brand. Journal of Business Research, 65, 1480-1486.

Kotler, \& Keller. (2012). Manajemen pemasaran. Edisi 12. Jakarta: Erlangga.

Kotler, P. (2008). Prinsip - prinsip pemasaran. Edisi 12, jilid 1 dan 2. Jakarta: Erlangga.

Kotler, P., \& Armstrong, G. (2004). Dasardasar pemasaran. Jakarta: Indeks.

Kumar, A., Bezawada, R., Rishika, R., R.Janakiranam, \& Kannan, P. (2016). From social to sale : the effects of firm generated content in social media on consumer behavior. Journal of Marketing, 80, 1-72.

Latan, H. (2013). Model persamaan struktural teori dan implementasi AMOS 21.0. Bandung: Alfabeta.

Mackenzie, S. B., \& Spreng., R. A. (1992). How does motivation moderate the impact of central and peripheral processing on brand attitudes and intentions? Journal of Consumer Research, 18, 519-529.

Morra, M. C., Ceruti, F., Chierinci, R., \& Gregorio, A. D. (2018). Social vs traditional madia communication: brand origin associations strike a chord. Journal of Research in Interactive Marketing, 12, $2-21$.

Muntinga, D. G., Smit, E., \& Moorman, M. (2012). Social media DNA: how brand characteristics shape COBRAs. Advances in Advertising Research, 3, 121-135.

Murphy, K. (2014). The influence of content on brand attitude and purchase intention 
within visual social media. Dublin: Dublin Business School.

Parikesit, \& Anggit, G. (2016). Fakta menarik pengguna instagram di Indonesia. Retrieved from CNN Indonesia website: https://m. cnnindonesia.com

Poulis, A., Rizomyliotis, I., \& Konstantoulaki, K. (2018). Do firms still need to be social? Firm generated content in social media. Information Technology \& People.

Pradhana, D., Duraipandiana, I., \& Sethib, D. (2014). Celebrity endorsment: how celebrity- brand- user personality conguence affects brand attitude and purchase intention. Journal of Marketing Communication.

Priester, J. R., Nayakankuppam, D., Fleming, M. A., \& Godel, J. (2004). The A2SC2 model: the influences of attitudese and attitude strength on considearation and choice. Journal of Consumer Research, 30, 574-587.

Schivinski, B., \& Dabrowski, D. (2014). The effect of social media communication on consumer perceptions of brands. Journal of Marketing Communication.

Schivinski, B., \& Dabrowski, D. (2015). The impact of brand communication on brand equity through facebook. Journal of Research in Interactive Marketing, 9, 3153.

Sekaran, U., \& Bougie, R. (2013). Research method for business: a skill- building aproach (seventh ed). New York: wiley.

Smith, A. N., Fischer, E., \& Yongjian, C. (2012).

How does brand-related user-generated content differ across youtube, facebook, and twitter? Journal of Interaction Marketing, 26.

Suryana, A., Zein, D., Sumartias, S., \& Gemiharto, I. (2019). Pengaruh strategi komunikasi pemasaran, budaya organisasi, karakteristik individu inovatif dan komitmen organisasional terhadap kinerja usaha kecil dan menengah. Jurnal Manajemen Komunikasi, 3(2), 185-201.

Virtanen, H., Bjork, P., \& Sjostrom, E. (2017). Follow for follow: marketing of a start-up company on instagram. Journal of Small Business and Enterprise Development.

Walgrem, C. J., Ruble, C. A., \& Donthu, N. (1995). Brand equity, brandd preference and purchase intetnion. Journal of Advertising, $24,25-40$.

Wang, A. (2009). Cross- channel integration of advertising: does personal involvement matter? Management Research News, $32(9), 858-873$.

Yan, J. (2011). Social media in Branding: Fulfilling a need. Journal of Brand Management, 18(9), 688-696.

Yoo, B., Donthu, N., \& Lee, S. (2000). An examination of selected marketing mix elements and brand equity. Journal of the Academy of Marketing Science, 28(2), 195-211. 